\title{
과학기술혁신(STI)과 교육: \\ 탄자니아 교육여건 개선을 위한 태블릿 기반 \\ 아동교육 앱 개발 사례
}

이혜경 (에누마(Enuma Inc.) 교육과정과 평가팀장)

목차

I. 서론

II. 과학기술혁신(STI)과 교육

1. 교육 분야의 ODA 목표와 탄자니아 교육 현황

2. 정보통신기술(Information and Communications Technology, ICT)과 교육

III. 에누마의 태블릿 기반 교육용 앱(Todo School) 개발 사례

1. 사례 기업(에누마)의 소개

2. XPRIZE Learning Competition

3. 토도 스쿨(Todo School)

4. 사용성 검사(Usability Test)

IV. 결론

참고문헌 


\section{I. 서론}

전 세계적으로 약 2 억 5 천만 명 (총 아동인구의 $1 / 8$ )의 아동들이 기초수준의 읽기, 쓰기, 셈하 기를 하지 못하며, 이중 5700 만 명의 어린이들은 기초교육을 전혀 받지 못하고 있다(UNESCO, 2014). 이는 각국 정부에 연간 미화 1,290 억 달러(한화 154 조 원)의 경제적 손실을 입히고 있다 (EFA GEM, 2013). 개도국의 이러한 열악한 교육환경의 주요인은 학교 및 교사의 절대 부족에 있다. 그러나 개도국에서 학교 설립, 교사 양성 등 전통적인 교육 시스템의 확장에 필요한 재원 과 인프라를 마련하는 일은 막대한 자본과 시간이 필요하다. ${ }^{1)}$

이에 우리나라를 비롯한 다수의 국제기구 및 공여국들은 과학기술혁신 (Science, Technology, and Innovation, STI)을 활용한 저비용의 혁신적인 대안을 마련하여 개도국 아동에게 양질의 교육을 제공하려 노력하고 있다. 특히 선진국을 중심으로 태블릿 $\mathrm{PC}$ 에 기반한 디지털 기초 교육 앱이 아동들의 흥미 유발, 높은 접근성, 개인화의 가능성 등의 장점으로 많은 관심을 받으면서 (Chiong \& Shuler, 2010), 저비용, 저전력의 모바일 기반 교육 혁신에 대한 기대가 각국 정부와 $\mathrm{NGO}$ 로부터 고조되고 있다. 본고에서는 탄자니아 초등교육의 질적 개선을 위한 태블릿 기반 교 육용 앱 개발 사례를 바탕으로, 교육 분야의 공적개발원조(Official Development Assistance, $\mathrm{ODA}$ )에서 STI의 적용이 갖는 의미와 기대되는 성과에 대해 알아보고자 한다.

\section{II. 과학기술혁신(STI)과 교육}

\section{1. 교육 분야의 ODA 목표와 탄자니아 교육 현황}

\section{가. SDG4 (양질의 교육 제공)}

지난 이십여 년 간 세계연합(United Nations, UN)과 산하 국제협력기구들은 전 세계 아동들 을 위해 무상교육의 기회를 확대하고자 노력해왔으며, 그 결과 초등학교(primary school) 취학 률은 상당한 증가를 보였다. 특히 사하라 아프리카 지역의 초등학교 취학률은 1990 년에 $52 \%$ 에 서 2012년에는 78\%로 비약적인 발전을 보였다2). 그러나 이러한 교육기회의 양적 확대가 반드시

1) 유네스코 통계연구소에서 최근 발표한 보고서에 따르면, SDG4 (양질의 교육제공과 평생교육) 달성을 위해 전 세계적으 로 270만 명의 초등학교 교사를 임용해야 하며, 그 수가 2020년에는 1,090만 명, 2030년에는 2,580만 명으로 늘어날 것으로 추산됨 (UNESCO, 2015).

2) SDGs에 대한 자세한 사항은 다음 홈페이지 참조: http://www.undp.org/content/undp/en/home/sustainable- 
양질의 교육과 연결되지 않았으며, 그로 인해 세계적으로 1 억 3 백만 명의 아동들은 여전히 기본적 인 읽고 쓰기 능력을 함양하지 못하고 있다. 이에 UN은 2015년 지속가능개발목표(Sustainable Development Goals, SDGs)를 채택하여 2030년까지 남녀불문 모든 아동들에게 양질의 초등 중등교육을 제공하여 의미 있는 학습 성장을 기대하는 SDG4를 발표하였다.

이에 한국국제협력단(Korea International Cooperation Agency, KOICA)에서도 교육의 질 적 개선을 추구하는 UN의 SDG4의 방향에 부합하여 학교 안팎에서 실제로 학습활동이 발생하도 록 학습효과를 보장하는 양질의 교육 콘텐츠를 제공하는 방안을 모색하고 있다. 에누마의 태블릿 에 기반한 교육용 앱 개발 사업은 이러한 노력의 일환으로 탄자니아 지역 아동들에게 양질의 교 육환경을 제공하여 세계가 당면한 교육문제에 대해 지속가능한 해결방법을 제시하고자 한다.

\section{나. 탄자니아의 교육 현황}

세계은행(World Bank)의 연구보고서(2016)에 따르면, 2014년 기준 탄자니아에서 최소한의 시설을 갖춘 학교 비율은 $40.9 \%$ 에 불과하며, 교사 1 인당 평균 학생 수는 43.4 명, 그리고 교과서를 가진 학생의 비율이 $25 \%$ 으로 교육 인프라 부족의 심각성을 보여주고 있다. 게다가 학교에 결근 하는 교사의 비율이 $14 \%$ 에 이르고, 심지어 출근만 하고 수업을 하지 않는 교사의 비율이 $46.5 \%$ 로 결과적으로 일별 실제 수업시간은 2 시간 27 분에 불과하다고 한다. 교사들의 학력수준 또한 낮아서 제대로 된 수업 콘텐츠 준비 및 전달이 불가능한 것으로 보고되었다.

이러한 교육여건의 열악함은 아동들의 기초학력에도 큰 영향을 미치고 있다. 미국 국제개발처 (United States International Development Cooperation Agency, USAID)가 2014년 발표한 탄자니아 기초학력평가 현황 보고서3)에서는 검사대상인 2학년 학생들 중 약 $60 \%$ 의 학생들만이 2 학년 수준에 적합한 읽기를 할 수 있으며, 수리영역에서는 약 $22 \%$ 의 학생들이 아주 간단한 뺄 셈 (예, 4-1=?)조차 하지 못하는 것으로 나타났다. USAID의 분석에 따르면, 학생들은 수학을 암기하는 과목으로 인지하고 있었으며 연산의 기본적인 개념을 이해하지 못하고 있다고 한다. USAID는 이러한 낮은 기초학력의 원인으로 (1) 체계적인 커리큘럼의 부재, (2) 과제 및 시험에 대한 교사의 피드백 부족, (3) 학생들의 자발적 참여의 부족, (4) 이해보다는 암기 위주의 교육방 식, (5) 교육보조제 및 도서관의 부족, (6) 가정에서의 교육기회 부족 등을 지적하고 있다.

개도국 취학아동인구의 양적확대를 추구했던 2014년 MDG2 (Millenium Development

development-goals (접속일: 2016.11.08.)

3) USAID (2014) 보고서의 자세한 사항은 다음 홈페이지 참조: https://www.eddataglobal.org/countries/index.cfm? fuseaction=pubDetail\&ID=682 (접속일: 2016.11.08.) 
Goal)에서 양질의 교육제공과 평생교육 달성이라는 SDG4로의 전환이 보여주듯이, 학교나 취학 아동의 수를 늘리는 양적 접근만으로는 탄자니아의 교육문제를 본질적으로 개선할 수 없다. 기본 시설 - 교사 - 교재가 없는 학교에 취학한 아동은 미취학 아동과 질적으로 다르지 않은 상황이며, 따라서 실제로 학습활동을 보장할 수 있는 양질의 교육 콘텐츠 제공 방안의 마련이 시급한 상황이다.

\section{2. 정보통신기술(Information and Communications Technology, ICT)과 교육}

최근 ICT의 비약적 발전은 인류의 삶에 큰 변화를 가져왔고, 또한 교육현장에서도 의미 있는 변화를 일으키고 있다. 그 중 아이패드로 대표되는 태블릿 $\mathrm{PC}$ 는 데스크탑이라 불리던 기존의 $\mathrm{PC}$ 와 달리 시각, 청각, 촉각을 아우르는 multiple sensory 기능을 탑재하여 학생들의 흥미를 유 발하며 학습과정을 강화하는 중요한 도구로 사용되고 있다(Castelluccio, 2010; Hill, 2011; Murphy, 2011; Carr, 2012). 특히 multiple sensory 기능을 갖고 있는 태블릿 PC와 상호반 응적인 게임기반 학습 (interactive game-based learning)의 만남은 오늘날의 학습 환경에 큰 변화를 주도하고 있다(Carr, 2012).

\section{가. 모바일 기술(Mobile Technology)의 발전과 교육}

이러한 과학기술의 혁신이 효과적인 교육도구를 제공함으로써 개발도상국의 열악한 교육환경 을 개선하고 학습기회의 확대에 기여할 수 있을 거라는 기대는 오래 전부터 있어왔고, 유네스코 를 포함한 여러 NGO 단체들은 모바일 기술의 활용을 통해 개발도상국 특히 아프리카 지역의 교 육여건을 개선하고자 노력하였다. 그러나 안타깝게도 각국 정부나 UN등의 글로벌 $\mathrm{NGO}$ 의 주도 에 의해 진행되어 온 이러한 사업들은 뚜렷한 학습 증진 성과를 증명해내지 못하였다.

실례로, 100 달러 미만의 저가 컴퓨터와 그 안에서 구동하는 교육 소프트웨어를 개발하여 가 장 낙후된 나라의 아이들에게 공급하고자 시작된 비영리사업인 One Laptop Per Child (OLPC) 사례(2005 - 2015)의 경우, 일반 모바일 시장의 제품에 비해 제품 사양과 가격경쟁력이 떨어지 는 것에 대한 비판을 받았고, 개도국에서의 학습 효과를 증명하지 못하였다.

2012년 상업용 안드로이드 모바일 태블릿과 일반 학습용 앱의 아프리카에서의 학습효과를 측 정하기 위해 에티오피아에서 진행된 2년간의 실험 또한 실패로 결론지어졌다. 이 실험의 디렉터 였던 Marcos Lemma의 분석(XPRIZE Summit, 2016)에 따르면, 전자기기에 대한 이해부족으 로 충전을 제대로 시키지 않거나 파손하는 등의 문제가 다수 발생하였으며 커뮤니티의 이해 부족 으로 기기를 교육 외(가정용 전등으로 사용하는 등)의 용도로 사용하는 문제가 발생하였다. 또한 지역상황과 아동들의 눈높이 맞는 학습용 앱의 부족으로 아이들이 쉽게 대부분의 앱들에 대해 흥 
미를 잃었다고 한다.

개도국에서 벌어진 이러한 사업의 실패의 원인에 대해 세계은행(World Bank)의 Mike Trucano는 다음과 같이 분석하였다.

(1) 하드웨어만 보급하고 그 외의 노력을 기울이지 않음

(2) $\mathrm{OECD}$ 학습 환경에 맞게 디자인한 프로젝트를 그대로 개도국에 적용함으로써 현지 상황에 부적합함

(3) 하드웨어를 보급한 후에야 학습용 컨탠츠에 대한 고민을 시작하여 외부에서 만들어진 학습 용 컨탠츠를 그대로 개도국에 적용함

(4) 학습 진행을 모니터하지 않음

(5) 교사의 교육을 소홀히 함

이러한 분석을 바탕으로 최근에는 개도국 상황에 맞는 양질의 학습 콘텐츠를 만드는 것을 목 표로, 이를 만들 수 있는 민간의 사업 주체들을 유인하는 컴피티션(competition) 기반의 프로젝 트가 활발히 진행되고 있다. 사례로는 2011년부터 USAID, 월드비전(World Vision), 호주 원조 청(Australian Aid, AusAid)이 협력하여 진행 중인 'All Children Reading: A Grand Challenge for Development' 사업, 노르웨이 국제개발청(Norwegian Agency for Development Cooperation, NORAD)의 주도 하에 학교에 가지 못하는 시리아 아동들에게 '재미있고 몰입적인 학습교재'를 제공하는 'Eduapps for Syria 사업(2015-2017)', 그리고 2015년부터 XPRIZE Foundation이 주최하고 유엔교육과학문화기구(United Nations Educational, Scientific and Cultural Organization, UNESCO), 유엔세계식량계획(World Food Programme, WFP), 탄자니 아 정부가 파트너로 참여하여 개도국의 아동들이 스스로 읽기/쓰기/셈하기를 배울 수 있는 태블 릿 교재를 개발하고자 하는 'XPRIZE Global Learning Competition 사업'4) 등이 있다.

\section{나. 게임에 기반한 학습 (Game-based learning)}

게임에 기반한 학습(Game-based learning, GBL)의 교육적 효율성에 대한 관심은 1980 년대 로 거슬러 올라간다. 많은 교육자들과 연구자들은 $\mathrm{GBL}$ 이 가지고 있는 아동의 높은 참여도와 동 기화를 눈여겨보고 기존의 교육 도구들을 대체할 매개로서 관심을 기울였다. 하지만, 아쉽게도

4) 에누마팀은 교육용 앱 토도스쿨 (Todo School)을 XPRIZE 재단이 주관하는 글로벌 교육 앱 경진대회 (Global Learning XPRIZE)에 출품하였다. 이 대회에서 입상할 시 (2017년 7월 발표) 2019년 4월 오픈소스로 공개되어 향후 유네스코 교 육 사업 제품에 투입될 예정이며, 입상하지 못할 시에는 개도국 정부 · UN 산하기구· NGO 등과 협력하여 개도국 교육 지원 사업을 위한 저비용 상품으로 개발하여 보급·확산할 계획이다. 
edutainment라고 불리던 교육용 게임들을 효과적으로 교수학습 환경과 연결시키지 못하였다 (Kerawalla \& Crook, 2005). 그러나 뉴 밀레니엄 시대에 들어와 모바일 기기의 혁신적인 발달 은 GBL에 대한 기대와 관심을 다시 불러일으키고 있다(Couse \& Chen, 2010).

오늘날 모바일 기술의 지원을 받은 GBL은 아동의 학습능력과 문제해결력을 증진하며 자신들 의 아이디어를 효과적으로 전달하는 교수·학습방법으로 관심을 받고 있다. 이는 또한 아동 개개 인의 학습 스타일, 목표, 그리고 흥미를 고려하는 새로운 학습문화의 창조를 촉진하고 있다. 이 러한 교육방법이 효과적이고 실제적인 교수도구로서 인식되고 있는 이유는, 이러한 학습방법이 (1) 설명보다는 행위를 사용하고, (2) 아동에게 즉각적인 피드백을 주며, (3) 다양한 학습 스타일과 기능들을 지원하며, (4) 기초적인 기능의 습득을 강화하며, (5) 개인의 학습 동기와 만족을 증진하 고, (6) 상호 반응하는 학습 환경(interactive learning environment)을 제공하기 때문이다 (Charles \& McAlister, 2004).

모바일 기술의 지원을 받는 GBL의 이러한 장점들을 인식한 수많은 학교들이 아이패드와 같은 태블릿 PC를 구입하여 교육에 사용하고 있으며(The New York Times, 2011), 전통적인 교과 서를 디지털 콘텐츠로 교체하는 학교들 또한 늘어나고 있다(The Washington Post, 2014). 또 한 이러한 기술의 지원을 받는 학습 환경에서 교육받은 아동들이 표준화된 학력검사에서 그렇지 않은 학습 환경에서 교육받은 아동들에 비해 더 나은 학력수준을 보이고 있다는 연구결과도 보고 되었다(Banister, 2010; Kukulaska-Hulme, 2009; Vernadakis et al., 2005).

\section{III. 에누마의 태블릿 기반 교육용 앱 (Todo School) 개발 사업 사례}

태블릿 기반 교육 앱은 기존의 컴퓨터에 비해 사용이 쉬워 0 8세 아동들도 디지털 콘텐츠의 접근이 가능하다는 장점을 가지고 있다. 특히 학습에 대한 흥미 유발과 자기주도학습 (self-directed learning)에서 높은 효과를 보임으로써 기존의 교사중심 수업방식을 보완하기 위 한 교육방법으로 선진국 학교 및 가정에서 적극적으로 활용되고 있다. 이렇게 선진국의 상업용 교육 제품들이 성공적으로 학교와 가정에서 활용되는 것과는 대조적으로, 지난 10 년간 개도국의 학력 증진을 도모하기 위해 설계된 모든 모바일 기술 기반 사업들은 의미 있는 교육적 효과를 내 지 못하였다. 이는 부유한 소비자 시장을 기반으로 하는 상용 교육 앱들과 비교해 개도국에서의 실험을 위해 사용된 앱 제품(주로 대학 연구실에서 제작)의 품질이 크게 떨어졌기 때문이다. 교 육현장에서 교사의 질이 교육의 효과를 좌우하듯, ICT기반 교육에서는 앱의 품질이 교육효과를 
좌우한다. 이른바, 앱을 구성하는 엔지니어링, 사운드, 그래픽 등 모든 요소들이 높은 수준에 도 달해야만 사용자인 아동의 몰입을 극대화할 수 있으며, 따라서 풍부한 개발경험과 고도의 전문성 을 가진 개발팀의 존재가 필수적이다.

제 I 장

\section{개}

습이 어려운 아이들도 독립적으로 학습할 수 있는 제품을 만들고자 하는 미션을 가지고 있다. 영 어의 Enumerate(하나하나 이름을 불러서 세다)라는 단어에서 따온 회사명 에누마는 한 명도 빠 짐없이 모든 아이들이 학습에 성공하는 세상을 만들고 싶은 꿈을 담고 있다.

에누마의 교육 앱은 교육 시장에서 흔히 사용되지 않는 최신의 게임 제작 기술을 도입하여 학 습 능력이 떨어지거나 학습의 기초가 부족한 아이들도 사용할 수 있도록 접근성(accessibility)을 강화한 제품이다. 현재까지 출시된 앱들로는 토도 수학(Todo Math), 토도 시계읽기, 토도 매트 릭스, Kid in Story, 자폐가 있는 아이들을 위한 Visual Schedule 등이 있다.

에누마의 대표 제품인 토도 수학은 3-8세 아동들을 위한 디지털 수학 학습 프로그램으로 2014년 iOS버전으로 출시되어 현재까지 300만 다운로드를 기록하고 있다. 토도 수학은 8개의 언어를 제공하며 1300 여 개 초등학교 교실에서 정규 수학 수업 교재로 사용될 뿐만 아니라, 2016년부터 중국 유치원 체인에 공급되는 등 세계적으로 교육적 가치를 인정받고 있다. 또한 토 도 수학은 Education \& Kids Conference의 Best Design Award(2013), Parent's Choice Gold Award(2015)를 수상하였고, 2016년은 미국의 소프트웨어 \& 정보 산업 협회가 주관하는 $\mathrm{CODiE} \mathrm{Award에서} \mathrm{최고의} \mathrm{영유아} \mathrm{교육} \mathrm{솔루션과} \mathrm{모바일} \mathrm{기기를} \mathrm{위한} \mathrm{최고의} \mathrm{교육} \mathrm{앱} \mathrm{두} \mathrm{부분에}$ 서 파이널리스트에 선정되었다. 이러한 수상경력과 실제 교육현장에서의 활용 사례들은 에누마가 태블릿에 기반한 교육용 앱 개발에서 풍부한 경험과 고도의 교육적·기술적 전문성을 지니고 있 음을 보여준다.

\section{XPRIZE Learning Competition}

에누마는 열악한 학습 환경에 놓인 아이들에게도 동등한 교육의 기회를 제공하고자 하는 바람 을 가지고 XPRIZE Global Learning Competition에 참가하고 있다. 이 대회는 개도국의 7-10세의 아동들이 교사의 도움 없이 기초적인 읽기/쓰기/셈하기를 익힐 수 있게 돕는 모바일 앱을 공모하는 사업으로, XPRIZE 재단이 UNESCO와 탄자니아 정부와 함께 추진 중이다. 사하 
라 이남 지역 아프리카 마을에 태양열 충전 설비와 태블릿을 배포한 후, 18 개월간 참여한 앱들의 필드 테스트를 진행하여 가장 우수한 성과를 낸 팀을 선정한다. 2014년부터 세계 130개의 팀이 현재 제품을 개발 중이며, 에누마는 한국인으로 이루어진 유일한 팀으로 참가 중이다. 현재 시제 품이 완성되었으며, 개도국 환경에 최적화한 제품을 만들기 위해 $\mathrm{KOICA}$ 와 협력하여 시제품의 사용성 검사(usability test)를 탄자니아 현지에서 시행하였고, 현재 기술성능과 교육적 효과 검 증을 위한 적합성 검사(Feasibility test)를 진행하고 있다.

\section{3. 토도 스쿨(Todo School)}

토도 스쿨은 기초 학력이 부족한 개도국 학생들에게 체계적으로 읽기, 쓰기, 셈하기를 가르치 기 위해 개발된 제품으로, 토도 수학의 기반 코드와 개발 경험이 많은 부분에서 활용되었다. 〈그 림1>에서 설명되듯이 토도 스쿨에서는 과학기술의 지원, 아동의 학습욕구에 대한 지원, 체계적 학습 이론에 근거한 커리큘럼 지원이 함께 이루어질 때 개도국 교육의 질적 개선이 이루어질 수 있다고 가정한다.

〈그림 1〉 토도 스쿨의 이론적 모형

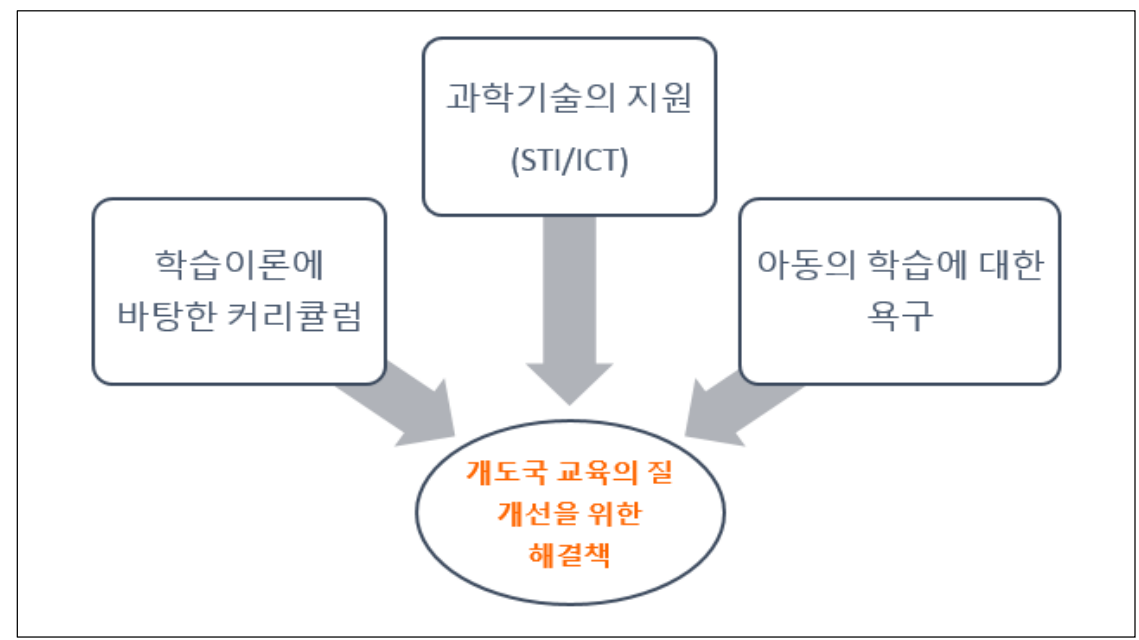

출처: 저자 작성

과학기술의 지원의 경우, 터치스크린(touch-screen)과 multi-sensory 기능 등을 사용하는 태블릿 $\mathrm{PC}$ 기술의 발달은 기존의 컴퓨터 사용이 낮설거나 어려운 개도국의 0-8세 아동들이 학 습에 대한 흥미를 가지고 개인화된 학습을 할 수 있게 도울 수 있다. 게다가 2016년 현재 저가 
태블릿 기기의 가격이 개당 35 불에서 계속 하락할 것으로 예상되며, 저전력 설계를 통해 휴대용 태양열 전지만으로도 사용이 가능하다는 점에서 기본적인 교육 인프라가 부족한 개도국의 현실에 적합하다.

디지털 게임에 기반한 학습(GBL)은 교사의 절대적 부족으로 어려움을 겪고 있는 개도국 어린 이들의 학습에 대한 흥미를 유발하여 스스로 학습할 수 있는 기회를 제공한다. 어린이들은 누구 나 배움의 욕구를 가지고 태어나며, 이러한 학습의 욕구를 지원할 수 있는 효과적인 교육용 도구 를 제공한다면 학생들은 열악한 교육환경 속에서도 스스로 학습을 수행할 수 있다. 실제로 태블 릿을 사용한 $\mathrm{GBL}$ 의 효과성을 연구한 최근의 연구들에서 학생들은 전통적인 교과서를 사용하여 학습한 학생들에 비해 높은 학습 동기화와 참여도를 보였으며, 이러한 태도의 변화는 학생들의 학업성취도에도 긍정적인 영향을 보였다(Li \& Pow, 2011; Houghton Mifflin Harcourt, 2012; Ash, 2011; Wright, 2012).

이러한 자기주도적인 학습을 성공으로 이끌기 위해서는 교육용 앱 콘텐츠의 질 또한 매우 중 요하다. 양질의 교육앱 콘텐츠를 제공하기 위해서는 아동의 언어, 수리 학습발달의 과학적 이론 에 근거하여 교육과정을 개발해야 한다. 앞서 이야기 하였듯이, ICT를 활용하여 아프리카 지역의 교육여건을 개선하려고 했던 여러 시도들이 의미 있는 성과를 보이지 못한 이유 중 하나는 하드 웨어의 보급에만 집중하고 실제로 학생들이 스스로 공부할 수 있는 효과적이고 체계적인 교육 콘 텐츠를 담고 있는 소프트웨어의 개발과 보급에 충분한 투자를 하지 않았기 때문이다.

이러한 이론적 모형을 바탕으로 토도 스쿨은 다음의 다섯 가지에 집중하여 설계되었다: Universal Design of Learning (UDL), (2) 탄자니아 교육여건 분석에 기반한 설계, (3) 탄자니 아의 문화 - 자연 환경을 차용한 디자인, (4) 사용자 중심 설계, (5) 오픈소스 기반의 설계. 토도 스쿨은 이러한 설계기준 하에 학령기 전 발달단계까지 포함하는 체계적인 커리큘럼으로 기초학력 여부에 관계없이 누구나 학습목표를 달성할 수 있도록 제작되었다.

\section{가. Universal Design of Learning (UDL)}

개도국 아동들의 소근육 발달, 시각 처리 능력, 청각 처리 능력, 인지 능력 등에 있어 편차가 클 것을 감안하여, 접근성 높은 학습 디자인 방법론인 Univeral Design of Learning (UDL)을 적극적으로 반영하였다. UDL은 학습도구를 디자인함에 있어 학습자들의 다양한 학습 스타일과 필요를 고려하는 디자인 방법론이며, 세 가지 핵심 원리에 기반하고 있다(Hall, Meyer, \& Reise, 2012). 첫째, 기본 개념을 학습자에게 설명함에 있어 여러 종류의 표현 수단을 사용한다. 둘째, 학습자들이 학습 개념을 보다 잘 이해하고, 문제해결 능력을 향상시킬 수 있도록 다양한 
행위와 표현 수단을 제공한다. 셋째, 학습자들의 다양한 참여 방법을 강구한다. 이러한 세 가지 $\mathrm{UDL}$ 원리를 토도 스쿨 디자인에 적용함으로써 아동들의 다양한 필요들을 충족시킬 수 있는 모 바일 학습 환경을 구현하였다.

\section{나. 탄자니아 교육환경 분석에 기반한 설계}

앞서 언급하였듯이, ICT를 활용한 그동안의 사업들이 실패한 이유 중 하나는 개도국 현지의 교육환경에 대한 고려 없이 현재 선진국에서 사용되는 제품을 그대로 사용하였기 때문이다. 이에 토도 스쿨은 탄자니아 현지 교육환경의 어려움을 분석하여 그에 대응하는 해결방안을 프로그램에 구현하고자 한다(〈그림2 참조〉).

첫째, 학교 시설 및 교재의 부족, 체계적인 학습 커리큘럼의 부재. 이 문제를 해결하기 위해 토도 스쿨은 유치원 전 과정부터 초등학교 2학년까지의 학습 커리큘럼을 체계적으로 제공하도록 설계하였다.

둘째, 교사의 학습 지도 의지와 피드백의 부족, 그에 따른 아동의 학습 의지 부족. 앞서 탄자 니아의 교육환경에 대한 기술에서 언급되었듯이 교사들의 결근이나 수업 부재의 빈도가 높은 상 황 속에서 아이들은 양질의 교육을 받을 수 없다. 이에 토도 스쿨에서는 즉각적인 피드백을 제공 하는 게임기반의 학습기법을 사용하여 아이들의 자기주도적인 학습이 가능하도록 설계하였다.

셋째, 아동의 낮은 기초 학습 능력 발달 수준과 가정에서의 다언어 사용. 교육 인프라의 부족 으로 아이들은 기초 학습 능력을 발달시킬 수 있는 충분한 기회를 제공받지 못하고 있다. 토도 스쿨은 초등학습에 필요한 기초적인 두뇌 발달 훈련 게임을 함께 제공하여 제품의 인지적·조작 적 접근성을 높이도록 설계하였다.

넷째, 교육 보조재 및 도서관, 가정에서의 교육 기회 부족. 이러한 문제점들 보완하기 위해 그 림판, 노트패드, 디지털 도서관을 제공하고 아동들이 자유롭게 탐색할 수 있는 디지털 교육 보조 재와 놀이 등을 포함하였다.

다섯째, 아동의 수준차가 심하고 각자에게 적절한 수준의 학습 방법을 찾기 어려움. 개인별 인 지적 격차에 대한 해법으로 실시간 평가와 그에 따른 개인화 프로그램을 제공하도록 설계하였다. 이로써 아동의 수준에 따른 적합한 활동을 추천할 수 있다. 
〈그림 2〉탄자니아 교육환경의 문제점과 그 해결책

\begin{tabular}{|c|c|}
\hline $\begin{array}{l}\text { 1. 학교 시설 및 교재 부족, } \\
\text { 체계적인 학습 커리큘럼 부재 }\end{array}$ & $\begin{array}{c}\text { 프리스쿨 수준부터 2학년까지의 } \\
\text { 체계적 학습 커리큘럼 제공 }\end{array}$ \\
\hline $\begin{array}{l}\text { 2. 교사의 학습 지도 의지와 피드백의 } \\
\text { 부족, 아동의 학습 의지 부족 }\end{array}$ & $\begin{array}{c}\text { 즉각적인 피드백을 제공하는 } \\
\text { 게임 기반의 학습 방법으로 } \\
\text { 자기주도적인 학습 흥미 유발 }\end{array}$ \\
\hline $\begin{array}{l}\text { 3. 아동의 낮은 기초 학습 능력 발달 } \\
\text { 수준과 가정에서의 다언어 사용 }\end{array}$ & $\begin{array}{c}\text { 초등학습에 필요한 기초적인 두뇌 발달 } \\
\text { 훈련을 함께 제공하고 제품의 } \\
\text { 인지적/조작적 접근성을 높임 }\end{array}$ \\
\hline $\begin{array}{l}\text { 4. 교육 보조재 및 도서관, 가정에서의 } \\
\text { 교육 기회 부족 }\end{array}$ & $\begin{array}{c}\text { 그림판, 노트패드, 라이브러리 제공 - } \\
\text { 아동들이 자유롭게 탐색할 수 있는 } \\
\text { 디지털 교보재와 놀이등을 수록 }\end{array}$ \\
\hline $\begin{array}{l}\text { 5. 아동의 수준차가 심하고 각자에게 } \\
\text { 적절한 수준의 학습 방법을 찾기 어려움 }\end{array}$ & $\begin{array}{c}\text { 실시간 평가와 개인화: } \\
\text { 아동의 수준에 따라 적합한 활동을 추천 }\end{array}$ \\
\hline
\end{tabular}

출처: 저자 작성

\section{다. 탄자니아 현지 환경을 차용한 디자인}

다양한 생활환경에 놓인 개도국 아동들이 친숙하게 이해하고 사용할 수 있도록 자연에서 차용한 그 래픽과 사운드를 사용하였다. 이는 탄자니아 아동들의 디지털 앱 접근성을 높여줄 것으로 기대한다.

〈그림 3〉 토도스쿨 앱 디자인

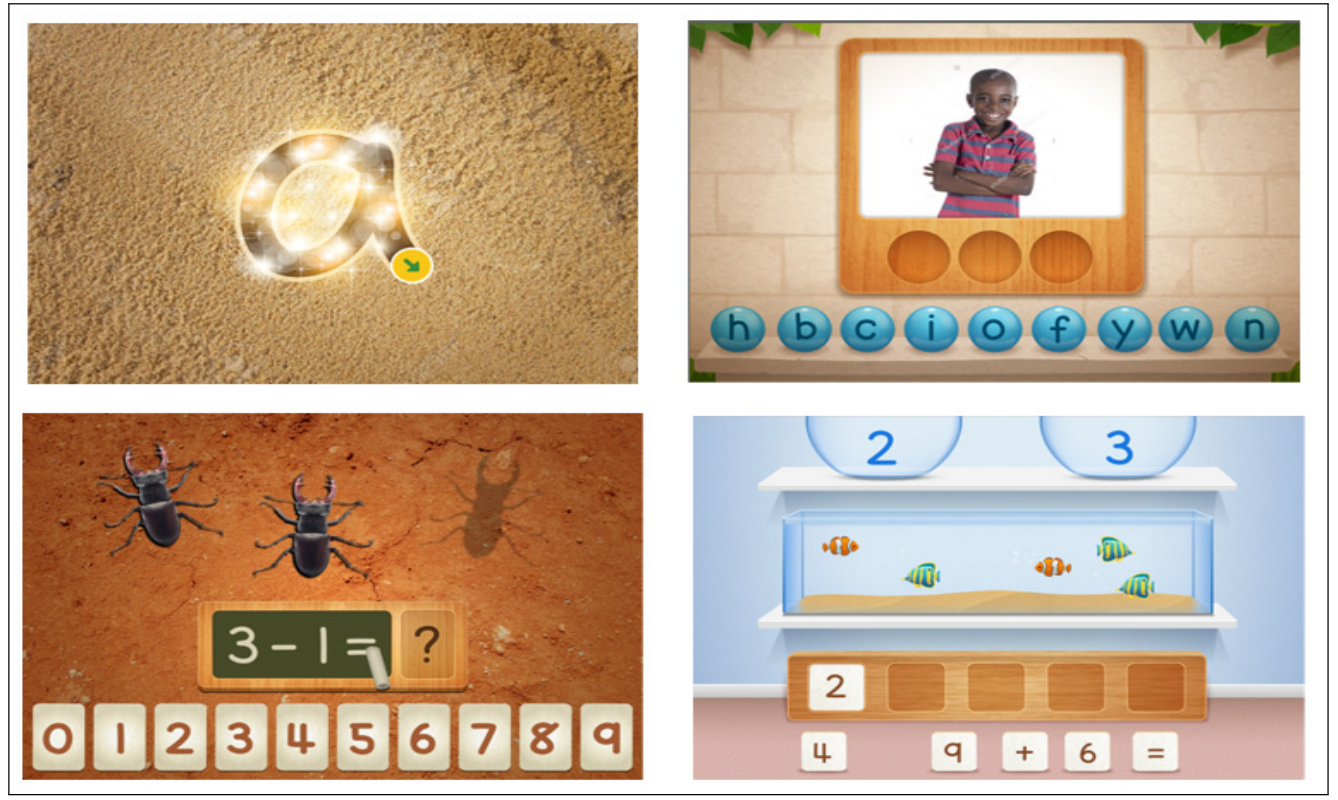

* 상단은 알파벳 따라쓰기, 스펠링 게임, 하단은 연산 문제, 수식 만들기 게임 출처: 토도 스쿨(Todo School) 


\section{라. 사용자 중심의 설계}

토도 스쿨은 $\mathrm{NGO}$ 인 굿네이버스와의 협력을 통해 탄자니아 지역에 대한 상세한 정보를 바탕으 로 사업의 대상자인 탄자니아 시골마을 7-10세의 아동들에게 최적화된 제품을 개발하고자 노력 하였다. 특히 2016년 7월 현지에서 행한 사용성(usability) 검사를 통해 아이들이 토도 스쿨을 얼마나 쉽게 이해하고 사용할 수 있는지 평가하고, 그 평가에 기반하여 제품을 개선해 나가고 있다. 2016년 11월 현재 탄자니아 다레살람과 바가모요 지역에서 적합성(feasibility) 검사가 이루어지고 있다. 또한 학습 앱 뿐만 아니라 생활에 도움이 되는 학습 비디오, 사진 찍기와 노트필기 기능 등 다양한 솔루션들을 함께 제공하여 사용자인 아이들이 다양하게 사용할 수 있도록 설계하였다.

\section{마. 오픈소스 기반의 설계}

토도 스쿨은 XPRIZE Global Competition 출품작이며, 따라서 오픈소스 기반으로 제작된다. 토도 스쿨은 오픈소스인 $\operatorname{COCOS~2DXㄹㅡㄹ~ㄱㅣㅂㅏㄴㅇㅡㄹㅗ~ㅈㅔㅈㅏㄱㄷㅚㅇㅓㅆㅇㅡㅁㅕ,~ㅁㅗㄷㅠㄹㅎㅘ~ㄱㅜㅈㅗㄹㅗ~ㅈㅔㅈㅏㄱㄷㅚㅇㅓ~ㄴㅗㅍㅇㅡㄴ~}$ 확장성을 가지고 있다. 오픈소스화를 통해 2019년 이후에 다양한 언어와 문화에 적합하게 개량 되어 각국의 $\mathrm{ICT}$ 솔루션의 기반이 될 것으로 기대한다.

\section{4. 사용성 검사(Usability Test)}

에누마팀은 굿네이버스의 협조를 받아 2016년 7월 1일부터 21일간 탄자니아와 케냐지역의 학 교를 방문하여 사용성 검사를 실시하였다. 이 방문의 목적은 현지의 교육 상황과 아동들의 학습 발달 정도를 확인하고, 동시에 시제품 토도 스쿨에 대한 현지 아이들의 반응을 확인하여 향후 토 도 스쿨의 개발과 개선에 필요한 정보를 얻기 위함이다. 현지 아동들의 게임 실행 모습을 관찰하 여 (1) 기기 조작 난이도, (2) 게임 규칙의 이해 정도, (3) 각 학습 게임별 선호도 등을 평가하였 다. 또한 교사와 $\mathrm{NGO}$ 관계자들을 상대로 토도 스쿨에서 사용되는 언어(영어와 스와힐리어)나 그 래픽 등의 적합성 역시 평가하였다. 


\section{〈그림 4〉사용성 검사 지역}

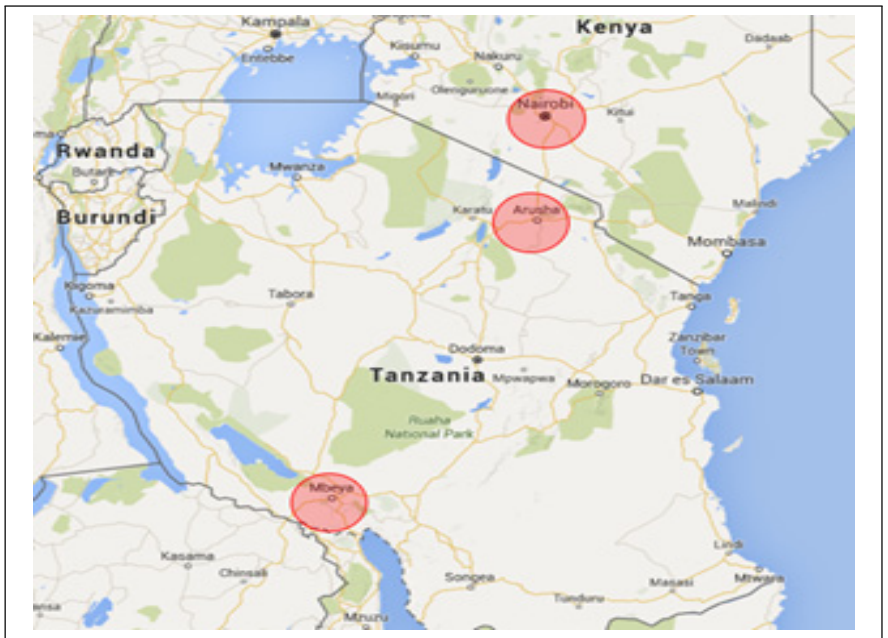

출처: google 홈페이지

\section{가. 사용성 검사 대상}

사용성 검사는 탄자니아와 케냐의 시골마을부터 대도시에 이르기까지 9 개 교육기관에서 이루 어졌다. 4 세부터 14 세까지 총 254 명의 남녀 아동들이 이 검사에 참여하였다(검사 대상 교육기관 과 참여 학생수, 그리고 각 학교의 특이사항에 관해서는 〈표1〉 참조).

〈표 1〉사용성 검사 참여 교육기관

\begin{tabular}{|c|c|c|c|c|}
\hline 번호 & 교육기관명 & 위치 & $\begin{array}{l}\text { 참여 } \\
\text { 학생수 }\end{array}$ & 특이사항 \\
\hline 1 & Insenzanya 초등학교 & $\begin{array}{l}\text { Nambinzo } \\
\text { 탄자니아 }\end{array}$ & $\begin{array}{c}\text { 74명 } \\
\text { (6세-13세) }\end{array}$ & 매우 외딴 시골학교로 수도와 전기시설도 부족함 \\
\hline 2 & Zawadi 어린이 센터 & $\begin{array}{l}\text { Karen } \\
\text { 케냐 }\end{array}$ & $\begin{array}{c}\text { 13명 } \\
\text { (4세-6세) }\end{array}$ & $\begin{array}{l}\text { 케냐의 수도 나이로비 근교에 위치한 어린이 } \\
\text { 센터로 NGO에서 운영 }\end{array}$ \\
\hline 3 & $\begin{array}{l}\text { Excel Emmanuel } \\
\text { 교육 센터 }\end{array}$ & $\begin{array}{l}\text { Ndango } \\
\text { 케냐 }\end{array}$ & $\begin{array}{c}\text { 22명 } \\
\text { (7세-11세) }\end{array}$ & $\begin{array}{l}\text { 사립초등학교, NGO에서 운영하며 교육기자재의 } \\
\text { 부족과 과밀학급 현상을 보임 }\end{array}$ \\
\hline 4 & Sharon 교육 센터 & $\begin{array}{l}\text { Kiambio } \\
\text { 케냐 }\end{array}$ & $\begin{array}{c}\text { 10명 } \\
\text { (4세-7세) }\end{array}$ & $\begin{array}{l}\text { 한 개 학급으로 이루어진 교육기관으로 NGO에서 } \\
\text { 운영 }\end{array}$ \\
\hline 5 & Peace Matunda Home & $\begin{array}{l}\text { Kimundo } \\
\text { 탄자니아 }\end{array}$ & $\begin{array}{c}\text { 35명 } \\
\text { (4세-14세) }\end{array}$ & Arusha지역에 있는 어린이 센터 \\
\hline 6 & Peace Matunda 학교 & $\begin{array}{l}\text { Kimundo } \\
\text { 탄자니아 } \\
\end{array}$ & $\begin{array}{c}\text { 20명 } \\
\text { (7세-8세) }\end{array}$ & 영어 사용 초등학교 \\
\hline 7 & Funguliwa 학교 & $\begin{array}{l}\text { Kimundo } \\
\text { 탄자니아 }\end{array}$ & $\begin{array}{c}\text { 30명 } \\
\text { (8세-9세) }\end{array}$ & 시골 마을 공립 초등학교 \\
\hline 8 & Akeri 학교 & $\begin{array}{l}\text { Akeri마을 } \\
\text { 탄자니아 } \\
\end{array}$ & $\begin{array}{c}\text { 10명 } \\
\text { (4-7학년) }\end{array}$ & 시골 마을 공립 초등학교 \\
\hline 9 & Muungano 초등학교 & $\begin{array}{l}\text { RiverTown } \\
\text { 탄자니아 }\end{array}$ & $\begin{array}{c}\text { 50명 } \\
\text { (7세-9세) }\end{array}$ & 대도시 초등학교 \\
\hline
\end{tabular}

출처: 저자 작성 


\section{나. 검사 방법}

이 사용성 검사는 시간과 장소 등에 대한 엄격한 실행 조건 없이 현지 학교 사정에 맞추어 이 루어졌다. 일반적으로 1 명에서 4 명까지의 아동들이 검사 장소에 모여 1 대 1 혹은 1 대 2 의 비율로 태블릿을 사용하였다. 연구자가 아이들에게 스마트폰이나 태블릿 $\mathrm{PC}$ 를 보여주며 이런 기기를 사 용해 본 적이 있는지 물어본 후, 아이들 스스로 토도 스쿨 게임을 실행하도록 하였다. 연구자는 아이들이 외부의 도움 없이 스스로 게임을 실행하는 모습을 관찰하며, 특히 다음 사항들을 중점 적으로 관찰, 기록하였다.

1. 아이들이 토도 스쿨 초기화면에 나오는 새알을 깨뜨려 시작할 수 있는가?

2. 아이들이 언어영역 새알과 수학영역 새알 구분하여 넘나들 수 있는가?

3. 아이들이 각각의 게임을 어떻게 실행하는지 이해하는가? (게임의 규칙 이해)

4. 아이들이 각각의 게임 내용을 이해하는가?

5 . 아이들이 어떻게 탭(tap)하고 드래그(drag)하는지 이해하는가?

6. 아이들이 서로 소통하는가?: 다른 아이들의 사용을 관찰하여 배우며, 또한 사용을 서로 도 와주는가?

7. 아이들이 게임들을 즐기고 있는가?

\section{다. 사용성 검사 결과}

현지 아동들에게 태블릿에 기반한 학습게임은 생소한 경험이었으나, 대부분의 아동들이 새알을 깨뜨려 게임을 시작하는 규칙을 비교적 쉽게 습득하였다. 특히 다른 아동들의 게임 실행을 관찰 하면서 더 빠르게 배우는 모습을 보였다. 다만 지역 간의 편차가 확인되었다. 도시에서 많이 떨 어져 있는 외진 마을의 학교(Insenzanya 초등학교, 탄자니아 Nambinzo 마을)에 다니는 아이들 의 경우, 대부분의 아이들이 태블릿의 스크린을 만지거나 터치하려고 하지 않았다. 연구자의 실 행 모습을 관찰하고 난 후인 둘째 날에서야 초기화면의 새알을 깨뜨려 게임을 실행할 수 있었다. 특히 이 지역 아동들은 태핑(tapping), 드래깅(dragging), 그리고 스와핑(swiping)과 같은 터치 스크린 기본 기능을 익히는데 다소 시간이 필요하였다.

Nambinzo마을의 Insenzanya 초등학교 아동들을 제외하고는 대부분의 아이들이 언어영역과 수학영역 게임 사이를 비교적 수월하게 넘나들었다. 아이들은 게임 시작-실행 규칙을 알아내기 위해서 스크린의 여기저기를 태핑(tapping)하였으며, 규칙을 스스로 알아낸 후에는 매우 기뼈하 는 모습을 보였다. 짝을 지어 게임을 실행하는 경우에는 서로 도우며 게임의 규칙을 알아내곤 하 
였다. 또한 아이들은 게임을 실행하는 규칙뿐만 아니라 게임 내용 역시 제대로 이해하며 토도 스 쿨을 사용하였다. 이는 단순히 신기한 기기를 만지고 조작하는 행위를 하는 것이 아니라 실제 학 습활동을 하고 있다는 것을 보여준다.

또 한 가지 눈여겨 볼 점은, 아이들이 짝을 지어 게임을 실행할 때 서로 협조하며 서로의 학습 을 도왔다는 점이다. 이러한 상호협력적인 학습 양상은 모든 검사 대상 교육기관에서 동일하게 나타났다. 서로 도와 게임의 규칙을 알아내는 것뿐만 아니라 서로 같은 게임을 동시에 진행하면 서 경쟁하는 것을 즐기기도 하였다. 토도 스쿨이 아동의 협력학습을 기대하고 디자인되지 않았음 에도 아이들은 스스로 자기들의 학습을 동기화하고 증진시키는 방법을 터득해내고 있었다.

아이들이 특별히 선호하는 게임은 없었으며 할 수 있는 한 여러 게임을 실행해 보려는 경우도 있었고, 한 가지 게임을 반복하여 실행하는 경우도 있었다. 이는 게임에 대한 선호 때문이기 보 다는 아동들 간의 학습 성향의 차이로 보인다. 아동의 학습 성향에 따라 어떤 아동들은 한 가지 게임을 마스터할 때까지 반복하는 것을 선호하고, 또 어떤 아동들은 다양한 게임들을 돌아다니며 흥미를 높이는 것을 선호하기도 한다.

이 지역에서 활동하고 있는 $\mathrm{NGO}$ 활동가들, 공립학교 교사와 교장들로부터 받은 토도 스쿨 게 임에 대한 피드백 역시 매우 긍정적이었다. NGO 활동가들은 그동안 모바일 기술에 기반한 학습 을 이용하여 아이들을 교육하고자 노력하여 왔다. 그러나 양질의 교육 프로그램 혹은 앱을 찾는 일이 어려웠다고 말하며, 토도 스쿨의 콘텐츠에 매우 깊은 인상을 받았다고 한다. 특히 인터넷 연결 없이 구동되는 토도 스쿨 같은 앱의 사용을 통해 난민캠프의 아동 교육을 향상시킬 수 있으 리라 기대하였다. 이 사용성 검사에 참여한 학교의 교사들과 교장들 역시 토도 스쿨의 콘텐츠와 게임 디자인에 큰 만족감을 보이며 향후 사용가능성에 대해 문의하였다. 교육전문가들은 모두 ICT의 발달이 교육에서 갖는 잠재성과 중요성에 대해 인식하고 있었으며, 아이들에게 더 많은 기회를 제공할 수 있게 되길 기대하였다.

\section{IV. 결론}

앞서 논의하였듯이 교육 분야의 $\mathrm{ODA}$ 의 목표는 교육기회의 양적 증가에서 교육의 질적 개선으 로 바뀌었다. 그러나, 탄자니아와 같은 개도국의 열악한 교육환경의 질적 개선은 막대한 시간과 자본이 필요하며, 이에 저비용 고효율의 혁신적인 대안을 찾고자 하는 노력이 필요하다. STI는 이러한 요구에 부응할 수 있는 잠재성을 지니고 있으며, 실제로 ICT의 발달과 더불어 교육 분야 
에 큰 변화가 일어나고 있다. 태블릿을 이용한 자기주도적 학습 프로그램 혹은 앱의 개발이 그것 이다. 이미 선진국 교육현장에서는 그 교육적 효과와 가치가 확인되어 성공적으로 교수-학습의 과정에 활용되고 있다.

개도국에서도 ICT를 활용한 교육혁신 시도가 여러 차례 있어왔다. 그러나 대부분 의미 있는 교육적 성과를 이루지 못하였으며, 그 주원인으로 체계적이고 양질의 교육 콘텐츠를 담고 있는 소프트웨어의 부재가 지적되었다. 세계적으로 이 문제점을 해결하기 위해서 새로운 사업들이 진 행되고 있으며, 에누마의 토도 스쿨 교육용 앱의 개발 사례도 그런 사업들 중 하나이다. 이미 본 문에서 언급하였듯이, 효과적인 교육용 앱의 개발에는 여러 가지 제반 조건이 필요하다. 개발자의 우수한 기술력과 과학적으로 검증된 학습 이론을 토대로 만들어진 교육 콘텐츠, 그리고 개도국 현지 교육적 제반 상황(아동들의 학습발달 정도, 학습 환경적 여건)을 고려한 앱의 개발이 그것 이다.

에누마의 토도 스쿨은 이러한 조건들에 대한 충분한 인식아래 개발되고 있다. 특히 탄자니아 현지를 방문하여 그 지역 아동들에 대한 실제적인 정보를 얻기 위한 노력을 기울이고 있다. 사용 자에 대한 제대로 된 이해 없이 사용자에게 적합한 제품을 만들 수는 없기 때문이다. 이미 사용 성 검사를 마쳤고, 적합성 검사를 진행 중이다. 사용성 검사의 경우, 검사가 이루어진 대부분의 학교에서 아동들이 토도 스쿨 게임에 큰 흥미를 보이며 기술적 어려움 없이 게임을 실행할 수 있 었다. 특히 XPRIZE 경진대회가 이루어지는 탄자니아의 Arusha 지역의 6-14세 아동들은 태블 릿을 편안하게 사용했으며, 게임을 진행하는 방법을 스스로 터득하고 대부분의 교육내용을 학습 할 수 있었다. 이 사용성 검사를 통해 에누마팀은 토도 스쿨의 현행 디자인과 개발 방향이 탄자 니아 현지 교육적 상황에 적절하다는 사실을 확인하였다. 현재 진행 중인 적합성 검사는 토도 스 쿨의 교육적 효과를 확인하는 연구로서, 3 주 간의 토도 스쿨 사용이 아동들의 학습 발달과 학력 증진에 효과적으로 기여할 수 있는지 확인할 예정이다. 


\section{〈참고문헌〉}

Ash, K. "Calif. district pushes digital-text initiative forward" posted on official website of Education Week Digital Directions (2011.02.04), available at http://www.edweek.org/dd/articles/2011/02/09/02books.h04.html (접속일: 2016.11.08.)

Banister, S. 2010. "Integrating the iPod touch in K-12 Education: Visions and vices". Computers in the Schools 27(2): 121-31

Carr, J. M., 2012. “Does math achievement h'APP'en when iPads and game-based learning are incorporated into fifth-grade mathematics instruction”. Journal of Information Technology Education: Research 11(1): 269-86

Castelluccio, M., 2010. “The table at work”. Strategic Finance 92(5): 59-60

Charles, D., \& McAlister, M., 2004. "Integrating ideas about invisible playgrounds from play theory into online educational digital games". International Conference on Entertainment Computing(ICEC). 3166: 598-601

Chiong, C., \& Shuler, C., 2010. "Learning: Is there an app for that? Investigations of young children's usage and learning with mobile devices and apps”. New York: The Joan Ganz Cooney Center at Sesame Workshop, available at http://www-tc.pbskids.org/read/files/cooney_learning_apps.pdf (접속일: 2016.11.08.)

Couse, L. J., \& Chen, D. W. 2010. "A tablet computer for young children? Exploring its viability for early childhood education”. Journal of Research on Technology in Education 43(1): 75-96

Hall, T. E., Meyer, A., \& Rose, D. H. (Eds.). 2012. Universal Design for Learning in the Classroom: Practical Applications. New York: Guilford Press Hill, R. A., 2011. "Mobile digital devices". Teacher Librarian 39(1): 22-6

Kerawalla, L., \& Crook, C., 2005. "From promises to practices: The fate of educational software in the home". Technology, Pedagogy and Education 14(1): 107-25 
Kerawalla, L., \& Crook, C., 2005. "From promises to practices: The fate of educational software in the home". Technology, Pedagogy and Education 14(1): 107-25

Kukulska-Hulme, A., 2009. "Will mobile learning change language learning?" ReCALL 21(02): 157-65

Li, S. C., \& Pow, J. C., 2011. "Affordance of deep infusion of one-to-one tablet-PCs into and beyond classroom”. International Journal of Instructional Media 38(4): 319-326

Murphy, G. D., 2011. "Post-PC devices: A summary of early iPad technology adoption in tertiary environments". E-Journal of Business Education \& Scholarship of Teaching 5(1): 18-32

USAID. 2014. "National Baseline Assessment For the 3Rs (Reading, Writing, and Arithmetic) using EGRA, EGMA, and SSME in Tanzania. EdData II Technical and Managerial Assistance, Task Number 24," available at https://www. eddataglobal.org/countries/index. cfm?fuseaction=pubDetail\&ID=6 82 (접속일: 2016.11.08.)

Vernadakis, N., Avgerinos, A., Tsitskari, E., \& Zachopoulou, E., 2005. "The use of computer assisted instruction in preschool education: Making teaching meaningful”. Early Childhood Education Journal 33(2): 99-104

World Bank. 2016. “Service Delivery Indicators: Tanzania - Education,” available at http://documents. worldbank.org/curated/en/738551467996696039/pdf/105994 -BRI-P146421-WB-SDI-Brief-Tanzania-EDU-final-PUBLIC.pdf（접속일: 2016. 11.08.)

Wright, A., 2012. "Tablets over textbooks". Communications of the ACM 55(3)

UNDP 홈페이지(SDGs 소개): http://www.undp.org/content/undp/en/home/ sustainable-development-goals (접속일: 2016.11.08.)

Google 홈페이지(탄자니아, 케냐지역 사용성 조사 지역 검색): google.com (접속일: 2016.11.08.) 